\title{
Organ Dysfunctions among Deaths in Critically III Patients
}

\author{
Leison Maharjan, ${ }^{1}$ Aarzoo Shah, ${ }^{2}$ Uday Bajracharya, ${ }^{1}$ Gambhir Shrestha ${ }^{3,4}$ \\ ${ }^{1}$ Blue Cross Hospital, Kathmandu, Nepal, ${ }^{2}$ Kathmandu Medical College, Kathmandu, Nepal, ${ }^{3}$ Department of Health \\ Services, Ministry of Health, Government of Nepal, Kathmandu, Nepal, ${ }^{4}$ School of Public Health \& Community \\ Medicine, B.P. Koirala Institute of Health Sciences, Dharan, Nepal.
}

\begin{abstract}
Background: Multiple organ failure is recognized as the final pathway preceding majority of deaths in intensive care unit. This study aims to find out the prevalence of organ dysfunctions/ failures in patients at the time of their demise irrespective of the underlying diseases in a tertiary care hospital.

Methods: This study was done in medical intensive care unit of Blue Cross Hospital. Medical records of all deceased patients in two years period were thoroughly reviewed retrospectively. Status of six organ systems was categorized into five sub-groups: No organ dysfunction, Mild organ dysfunction, Acute organ failure, Acute-on-chronic organ failure, and Chronic organ failure. The proportion of organ dysfunction involved was analyzed along with other variables.

Results: Among 204 deaths, majority 165 (80.9\%) had Multiple Organ Dysfunction Syndrome. Circulatory system was most affected system with "acute organ failure" 134 (65.5\%) followed by acute respiratory failure 128 (62.7\%), and acute neurologic failure 114 (55.8\%). Neurologic system was most affected with "mild organ dysfunction" 47 (23\%) followed by Respiratory system and Renal system. Of the patients who had chronic organ failures at the time of admission, 72 (81.8\%) developed "acute-on-chronic failures".

Conclusions: Multiple Organ Dysfunction Syndrome was present in the majority of deaths in critically ill patients. Most common acutely failed organ was the circulatory system.

Keywords: Intensive care unit; multiple organ dysfunction syndrome; organ dysfunction; organ failure.
\end{abstract}

\section{INTRODUCTION}

The Intensive Care Unit (ICU) is the highest mortality unit in any hospital. Mortality in the ICU is mostly multi factorial, and multiple organ failure is the main cause of mortality in these patients. It is recognised as the final pathway preceding death in critically ill patients. ${ }^{1}$ Organ dysfunction is an independent prognostic factor for ICU mortality. ${ }^{2}$ Such data helps the hospital administrators, clinicians, and policy makers to formulate protocols and policies for the improvement of the outcome as well as management of these patients.

Our study aims to find out the prevalence of organ dysfunctions/ failures in patients at the time of their demise irrespective of the underlying diseases in a tertiary care center. The knowledge, thus obtained can be valuable in a critically ill patient to improve the overall outcome..$^{2,3}$

\section{METHODS}

A descriptive retrospective study was conducted. All deceased patients' record files during two years period from December 2012 to December 2014 were obtained from the In-Patient record section of Blue Cross Hospital, Kathmandu and examined retrospectively. All the patients were adults (Age >14years) in Intensive Care Unit of the hospital. Blue Cross Hospital is a tertiary care hospital located in the centre of Kathmandu with 10-bedded ICU consisting of 4 ventilators and a dialysis unit. Nepal Health Research Council approved ethical consideration for the study. Permission to conduct the study in the hospital was taken from the hospital director.

Patients' data were obtained from the hospital record section which were thoroughly studied. Status of six organ system of each case was categorised into five
DOI: $\quad$ http://dx.doi.org/10.3126/

jnhrc.v15i3.18844
Correspondence: Leison Maharjan, Blue Cross Hospital, Kathmandu, Nepal. Email: leison.maharjan@gmail.com, Phone: +9779841190258. 
sub-groups: (i) No organ dysfunction, (ii) Mild organ dysfunction, (iii) Acute organ failure, (iv) Acute on chronic organ failure, and (v) Chronic organ failure. No organ dysfunction, mild organ dysfunction and acute organ failure were determined according to Sequential Organ Failure Assessment (SOFA) and Modified Sequential Organ Failure Assessment (MSOFA) while Chronic Liver Failure-Sequential Organ Failure Assessment (CLIFSOFA), Kidney Disease Improving Global Outcome (KDIGO) guidelines, and American College of Physicians (ACP)definition were used to define acute on chronic organ failure. ${ }^{4,5}$ SOFA 1 and 2 was used to designate organ dysfunction/failure into "Mild organ dysfunction" category, and SOFA 2 and 3 was used to categorise into "Acute organ failure" category (Table 1). The SOFA is useful in quantifying dysfunction in individual organ systems over time which is not possible with most other ICU scoring systems. ${ }^{6}$ Previously established diagnosis/ or newly diagnosed cases were placed under "Chronic organ failure”. Each case was also categorised according to standard sepsis classification. ${ }^{7}$

Multiple Organ Dysfunction Syndrome (MODS) is defined as a clinical syndrome characterised by the development of progressive and potentially reversible physiologic dysfunction in 2 or more organs or organ systems that are induced by a variety of acute insults, including (but not limited to) sepsis. MODS has conventionally been defined in terms of involvement of six organ systems, namely - pulmonary, renal, hepatic, central neurologic, cardiovascular, and hematologic systems. ${ }^{8}$

Data was entered in MS-EXCEL 2007 software and analysed in Statistical Package for Social Sciences (SPSS, version 17). Descriptive data analysis was used to show the proportion of organ dysfunction according to the systems involved and also to show other variables.

\section{Table 1. Categorization of organ status according to the systems.}

\begin{tabular}{|c|c|c|c|c|}
\hline Systems & $\begin{array}{l}\text { No organ } \\
\text { dysfunction }\end{array}$ & Mild organ dysfunction & Acute organ Failure & $\begin{array}{l}\text { Chronic } \\
\text { Organ } \\
\text { Failure }\end{array}$ \\
\hline
\end{tabular}

\begin{tabular}{|c|c|c|c|c|}
\hline $\begin{array}{l}\text { Respiratory* } \\
\mathrm{PaO} 2 / \mathrm{FiO} 2 \text { or } \\
(\mathrm{SpO} 2 / \mathrm{FiO} \text { ) }\end{array}$ & $>400$ & $\begin{array}{l}\leq 400 \text { or } \\
(\mathrm{SpO} 2 / \mathrm{FiO} 2 \leq 400)\end{array}$ & $\begin{array}{l}\leq 200 \text { or } \\
(\mathrm{SpO} 2 / \mathrm{FiO} 2 \leq 235)\end{array}$ & $\begin{array}{l}\text { Any degree of } \\
\text { respiratory acidosis } \\
\text { or worsening of } \\
\text { respiratory symptoms } \\
\text { on previously known } \\
\text { chronic respiratory } \\
\text { failure. (ACP 2011) }\end{array}$ \\
\hline $\begin{array}{l}\text { Coagulation } \\
\text { Platelets }\end{array}$ & $\begin{array}{l}>1,50,000 / \\
\mathrm{cc}\end{array}$ & $\leq 1,50,000 / \mathrm{cc}$ & $\leq 50,000 / \mathrm{cc}$ & - \\
\hline $\begin{array}{l}\text { Hepatic* } \\
\text { Bilirubin }\end{array}$ & $<1.2 \mathrm{mg} / \mathrm{dl}$ & $\begin{array}{l}\geq 1.2 \mathrm{mg} / \mathrm{dl} \text { or } \\
\text { absence of jaundice }\end{array}$ & $\begin{array}{l}\geq 6 \mathrm{mg} / \mathrm{dl} \text { or } \\
\text { presence of jaundice }\end{array}$ & CLIF SOFA \\
\hline $\begin{array}{l}\text { Circulatory } \\
\text { Blood } \\
\text { pressure } \\
\text { status }\end{array}$ & $\begin{array}{l}\text { No } \\
\text { hypotension }\end{array}$ & $\begin{array}{l}\text { MAP }<70 \mathrm{~mm} \mathrm{Hg} \text { or } \\
\text { Dopamine } \leq 5 \mathrm{mcg} / \mathrm{kg} / \\
\text { min or Dobutamine any } \\
\text { dose }\end{array}$ & $\begin{array}{l}\text { Dopamine }>5 \mathrm{mcg} / \\
\mathrm{kg} / \mathrm{min} \text { or } \\
\text { Norepinephrine any } \\
\text { dose or Epinephrine } \\
\text { any dose }\end{array}$ & $\begin{array}{l}\text { Previously known } \\
\text { chronic circulatory } \\
\text { failure which meets } \\
\text { SOFA } 3 \text { \& } 4 \text { criteria }\end{array}$ \\
\hline $\begin{array}{l}\text { Neurologic } \\
\text { GCS in } \\
\text { absence of } \\
\text { sedation }\end{array}$ & 15 & $10-14$ & $3-9$ & - \\
\hline $\begin{array}{l}\text { Renal } \\
\text { Creatinine or } \\
\text { urine output }\end{array}$ & $<1.2 \mathrm{mg} / \mathrm{dl}$ & $>1.2 \mathrm{mg} / \mathrm{dl}$ & $\begin{array}{l}\geq 3.5 \mathrm{mg} / \mathrm{dl} \text { or } \\
\text { urine output } \\
<500 \mathrm{ml} / 24 \mathrm{hr}\end{array}$ & KDIGO AKI GUIDELINES \\
\hline
\end{tabular}

*MSOFA was used only when there was the unavailability of SOFA parameters - PaO2 \& Bilirubin.

Chronic Organ Failure - previously established diagnosis/ or newly diagnosed

a) For Acute in Chronic Liver Failure, CLIF SOFA was used to estimate MODS. (INR $>2.5$ or Platelets $<20,000 / c c$, Bilirubin $\geq 12$

$\mathrm{mg} / \mathrm{dl}$, $\mathrm{HE} 3$ or $4, \mathrm{Cr} \geq 2 \mathrm{mg} / \mathrm{dl}$ or renal replacement)

b) For Acute in Chronic Renal Failure, KDIGO AKI GUIDELINES was used. ( $\mathrm{Cr}>1.5 \mathrm{mg} / \mathrm{dl} X$ 7days)

c) For Acute in Chronic Respiratory Failure, the definition of ACP 2011 was used (Any degree of respiratory acidosis or worsening of respiratory symptoms on previously known chronic respiratory failure.) 


\section{RESULTS}

In total, 220 deaths occurred out of 1055 admissions in the ICU during the two-year study period with the death rate of $20.8 \%$. Out of 220 deaths, only 204 record files were included in our study because 13 files were not accessible, and three record files didn't meet the criteria of inclusion as death occurred within one hour of admission. Among the deaths, 124 (60.8\%) were males and $80(39.2 \%)$ were females. The mean age was found to be 57.8 years while the highest number of deaths was recorded in "60-80" age group 76(37.3\%). Referral from other hospitals $148(72.5 \%)$ accounted for most of the admission cases in the Blue Cross Hospital ICU. Most of them died within less than 3 days of ICU stay 147 (72\%) despite only $38(18.6 \%)$ cases with do not resuscitate consent (Table 2).

\begin{tabular}{|c|c|}
\hline Variables & n (\%) \\
\hline Gender: Male & $124(60.8)$ \\
\hline \multicolumn{2}{|l|}{ Age (in years) } \\
\hline$<40$ & $44(21.6)$ \\
\hline $40-60$ & 61 (29.9) \\
\hline$>60$ & $99(48.6)$ \\
\hline \multicolumn{2}{|l|}{ Site prior to Admission } \\
\hline Other hospitals & $148(72.5)$ \\
\hline Emergency department & $31(15.2)$ \\
\hline Post-operative & $7(3.4)$ \\
\hline Ward & $17(8.3)$ \\
\hline Dialysis & $1(0.5)$ \\
\hline
\end{tabular}

Highest Pulse within 1 hour of admission (per minute)

\begin{tabular}{rr|}
\hline$<60$ & $7(3.4)$ \\
\hline $60-100$ & $74(36.3)$ \\
\hline$>100$ & $123(60.3)$ \\
\hline $\begin{aligned} \text { Lowest Systolic BP within 1 hour of } \\
\text { admission }(\mathrm{mm} \mathrm{Hg})\end{aligned}$ \\
\hline$<90$ & $52(25.5)$ \\
\hline $90-120$ & $66(32.4)$ \\
\hline $120-140$ & $35(17.2)$ \\
\hline $140-160$ & $28(13.7)$ \\
\hline$>160$ & $23(11.3)$ \\
\hline
\end{tabular}

\begin{tabular}{|c|c|}
\hline \multicolumn{2}{|l|}{ GCS on Admission } \\
\hline $3-9$ & $103(50.5)$ \\
\hline $10-14$ & $28(13.7)$ \\
\hline 15 & $73(35.8)$ \\
\hline \multicolumn{2}{|l|}{ ICU stay duration (in days) } \\
\hline$<3$ & $147(72.0)$ \\
\hline $3-6$ & $27(13.2)$ \\
\hline$>6$ & $30(14.8)$ \\
\hline Do Not Resuscitate consent: Yes & $38(18.6)$ \\
\hline \multicolumn{2}{|l|}{ Sepsis classification } \\
\hline No infection & $14(6.9)$ \\
\hline Infection & $5(2.5)$ \\
\hline SIRS & $17(8.3)$ \\
\hline Sepsis & $3(1.5)$ \\
\hline MODS & $165(80.9)$ \\
\hline $\begin{array}{l}\text { Ventilator including non-invasive: } \\
\text { Yes }\end{array}$ & $133(65.2)$ \\
\hline Vasopressors/ inotropes usage: Yes & $146(71.6)$ \\
\hline
\end{tabular}

At the time of ICU admission, $60.3 \%$ had tachycardia and only $3.4 \%$ had bradycardia. Similarly, $49.6 \%$ of the patients had normal BP while $25.5 \%$ were hypotensive. Half of the patients had GCS nine or less at the time of admission while $35.8 \%$ had normal GCS. In about $65.2 \%$ cases, ventilator was used and $71.6 \%$ were on vasopressor or inotropes support (Table 2). Leading cause of death was Respiratory disease $(30.4 \%)$, followed by Neurological disease (16.7\%) and Renal disease (16.2\%).

The majority of the cases ( $80.9 \%$ deaths) had MODS. The neurologic system was most affected with "mild organ dysfunction" (23\%) followed by the Respiratory system (16.6\%) and Renal system (12.7\%). Circulatory system was the most affected system with "acute organ failure" (65.5\%) followed by acute respiratory failure $(62.7 \%)$, and acute neurologic failure (55.8\%).Among $43.1 \%$ who had chronic organ failures at the time ofadmission, $81.8 \%$ developed "acute on chronic failures". Among them,all chronic respiratory failures and $76.6 \%$ of chronic renal failures developed acute on chronic failures (Table 3 ).

Among MODS, most of the patients had 3 organ system dysfunctions (31.9\%) with a combination of respiratory, neurologic, and circulatory system (Table 4). Continuous assessments of organ failures during an ICU admission are more useful than scores measured at admission to 
Table 3. Distribution according to the organ status and systems involved.

\begin{tabular}{|c|c|c|c|c|c|}
\hline Systems & $\begin{array}{r}\text { No organ } \\
\text { dysfunction }\end{array}$ & $\begin{array}{l}\text { Mild organ } \\
\text { dysfunction }\end{array}$ & Acute Organ Failure & $\begin{array}{l}\text { Acute on } \\
\text { Chronic }\end{array}$ & $\begin{array}{r}\text { Chronic Organ } \\
\text { Failure }\end{array}$ \\
\hline Respiratory & 9 & 34 & 128 & 33 & - \\
\hline Coagulation & 161 & 15 & 28 & - & - \\
\hline Hepatic & 167 & 13 & 3 & 14 & 7 \\
\hline Circulatory & 56 & 6 & 134 & 6 & 2 \\
\hline Neurologic & 43 & 47 & 114 & - & - \\
\hline Renal & 108 & 26 & 40 & 23 & 7 \\
\hline
\end{tabular}

determine the outcome and to compare ICUs. ${ }^{6}$

\section{Table 4. Number of systems dysfunction* involved} $(n=204)$.

Number of systems dysfunction involved

n (\%)

\begin{tabular}{lr}
0 & $1(0.5)$ \\
1 & $10(4.9)$ \\
2 & $45(22.1)$ \\
3 & $65(31.9)$ \\
4 & $54(26.5)$ \\
6 & $21(10.3)$ \\
* Systems dysfunction includes mild organ dysfunction, \\
acute organ failure \& acute on chronic failure. \\
\hline
\end{tabular}

\begin{tabular}{|c|c|c|c|c|c|c|c|}
\hline \multirow{2}{*}{$\begin{array}{l}\text { Types } \\
\text { of organ } \\
\text { dysfunction }\end{array}$} & \multicolumn{7}{|c|}{ Number of systems involved } \\
\hline & 0 & 1 & 2 & 3 & 4 & 5 & 6 \\
\hline $\begin{array}{l}\text { Mild organ } \\
\text { dysfunction }\end{array}$ & 98 & 75 & 27 & 4 & - & - & - \\
\hline $\begin{array}{l}\text { Acute organ } \\
\text { failure }\end{array}$ & 12 & 47 & 65 & 56 & 18 & 6 & - \\
\hline $\begin{array}{l}\text { Acute on } \\
\text { chronic } \\
\text { organ } \\
\text { failure }\end{array}$ & 132 & 68 & 4 & - & - & - & - \\
\hline $\begin{array}{l}\text { Chronic } \\
\text { organ } \\
\text { failure }\end{array}$ & 188 & 16 & - & - & - & - & - \\
\hline
\end{tabular}

\section{DISCUSSION}

In our study, we found ICU death rate to be $20.8 \%$, which is similar to a study done by Sharma in TUTH in which death rate was found to be $26.2 \%$ which shows that there is an insignificant variation in death rate between government and private hospitals. ${ }^{9}$ Also, the rate is similar to other developing countries like Morocco where ICU death rate is $23 \%$ and India $38 \% .^{10,11}$ However, compared to USA ICUs (8-19\%), our death rates in ICU is slightly higher and also median ICU stay was lesser which could be due to the lack of adequate critical care management. ${ }^{12-14}$

In this study, we found that $72.5 \%$ deaths occurred in those patients received from the other hospitals. The plausible reasons for such a high number could be due to late referral, inadequately equipped ambulances, poor patient transfer system, or few ICU facilities available in hospitals of Kathmandu. ${ }^{15}$ About $18.6 \%$ of DNR is quite high in comparison to other studies due to possible unaffordability of the hospital services by the patients' families and also due to lack of knowledge of medical insurances facilities. ${ }^{16}$

This study also showed that the mean ICU stay was 1.3 days, which is slightly less than that found in a Scottish ICU study among 873 patients (2.3days). ${ }^{16}$ This could be explained by the lack of adequate and well-equipped ICU facilities and universal gold standard ICU protocols in most of the hospitals. Other reason could be due to the fact that most of the patients in our study were referred from other hospitals. As many patients couldn't afford the ICU hospital services, this could be another reason for the disparity in our findings.

Though $60 \%$ of patients had tachycardia and $25.5 \%$ were hypotensive at the time of admission, yet $69.6 \%$ developed circulatory failure over time. $50.5 \%$ had GCS $<10$ at admissions compared to $55.88 \%$ ultimately undergoing neurologic failure during their ICU stay.

Majority of them had MODS (80.88\%) which is in accordance with a study done by Mayr et al. in which they found acute MODS as commonest cause of death contributing to $47 \%$ out of 353 ICU patients. ${ }^{17}$ Our study also found that about $72 \%$ of the patients died within 3 days of ICU stay. This finding is suggestive of 
development of early MODS during the course of stay and presence of multiple co-morbidities in a single patient further complicating the cases. It could also point to the lack of ICU facilities in other hospitals thus prompting them to refer complex cases to other hospitals and thus increasing the mortality.

The most common mild organ dysfunction was neurologic failure while the most common acute organ failure was cardiovascular (68.6\% of deaths) which is consistent with the prospective study done by Lakhey et al in patients admitted with sepsis in ICU in which they found circulatory system was the most common failing organ $(82.1 \%) .{ }^{18} \mathrm{~A}$ multicenter cohort study by $\mathrm{Nfor}$ et al has shown a strong independent association between ICU death and cardiovascular failure. ${ }^{6}$ Among MODS, most of the patients had 3 organ system dysfunctions (31.9\%) with a combination of respiratory, neurologic, and circulatory system. Mayr et al found neurologic failure and cardiovascular failure as two most important risk factors for death in ICU with risk ratio of 16.07 (95\% confidence interval 8.3 to 31.4 ) and 11.83 (95\% confidence interval 5.2 to 27.1$).{ }^{17}$

There are some limitations to this study. Firstly, our study was retrospective and done in a single ICU, and thus cannot be generalised. Secondly, majority of the cases were medical. Thirdly, the sample size was small. Moreover, $\mathrm{PaO} 2$ and bilirubin couldn't be accessed which prompted the use of MSOFA instead of SOFA. However, this study can be used to compare data among other ICUs.

This study recommends a further research be undertaken around the country to determine the organ dysfunction status among the critically ill patients using standardised tools so that the findings may be compared and generalised.

\section{CONCLUSIONS}

MODS was present in the majority of deaths in critically ill patients in ICU. Most common acutely failed organ was the circulatory system. Besides treating the underlying cause, formulating effective protocols to closely monitor the functions of the individual organs at risk is a must to reduce the prevalence of MODS and hence overall mortality in ICU.

\section{REFERENCES}

1. El-Menyar A, Al Thani H, Zakaria E, Zarour A, Tuma M, AbdulRH,et al. Multiple Organ Dysfunction Syndrome (MODS): is it preventable or inevitable? Int J Clin Med. 2013;3(07):722-30.[Link]
2. Umegaki T, Ikai H, Imanaka Y.The impact of acute organ dysfunction on patients' mortality with severe sepsis.J Anaesthesiol Clin Pharmacol. 2011;27:180-4.[FullText]

3. Rapsang AG, Shyam DC.Scoring systems in the intensive care unit: A compendium.Indian J Crit Care Med. 2014;18:220-8.[FullText]

4. Vincent JL, Moreno R, Takala J, Willatts S, De Mendonça A, Bruining H, et al. The SOFA (Sepsis-related Organ Failure Assessment) score to describe organ dysfunction/ failure. Intensive Care Med. 1996;22(7):707-10.[PubMed]

5. Grissom CK, Brown SM, Kuttler KG, Boltax JP, Jones J, Jephson AR, et al.A modified sequential organ failure assessment score for critical care triage. Disaster Med Public Health Prep. 2010;4:277-84.[PubMed]

6. Nfor TK, Walsh TS, Prescott RJ.The impact of organ failures and their relationship with outcome in intensive care: Analysis of a prospective multicentre database of adult admissions. Anaesthesia. 2006;61:731-8.[PubMed]

7. Bone RC, Balk RA, Cerra FB, Dellinger RP, Fein AM, Knaus WA, et al.Definitions for sepsis and organ failure and guidelines for the use of innovative therapies in sepsis. In Chest. 1992;101:1644-1655.[PubMed]

8. Mohan A. Multiple organ dysfunction syndrome (MODS) in the medical ICU, challenges and opportunities: Indian Perspective (Doctoral dissertation, Sri Venkateswara Institute of Medical Sciences). Available at: [Link]

9. Sharma NR. Outcome of intubated post-surgical cases in intensive care unit inTribhuvan university teaching hospital, Nepal. Journal of Institute of Medicine.2007;22;27(3). Available at:[Link]

10. Zeggwagh A, Mouad H, Dendane T, Abidi K, Belayachi J, Madani N, et al.Preventability of death in a medical intensive care unit at a university hospital in a developing country. Indian J Crit Care Med. 2014;18:88-94. [PubMed]

11. Sampath S, Fay MP, Pais P. Use of the logistic organ dysfunction system to study mortality in an Indian intensive care unit. Natl Med J India. 1999;12:258-261.[PubMed]

12. Angus DC, Linde-Zwirble WT, Sirio CA, Rotondi AJ, Chelluri L, Newbold RC 3rd, et al.The effect of managed care on ICU length of stay: implications for medicare. JAMA. 1996;276:1075-1082.[PubMed]

13. Wu AW, Pronovost P, Morlock L. ICU incident reporting systems. J Crit Care. 2002;17:86-94.[PubMed] 
14. Young MP, Birkmeyer JD. Potential reduction in mortality rates using an intensivist model to manage intensive care units. Eff Clin Pract. 2003;3:284-9.[PubMed]

15. Shrestha RR, Bajracharya PV. A survey of adult intensive care units in Kathmandu Valley. Post-Graduate Medical Journal of NAMS. 2011;31;11(02). Available at: [Link]

16. Salottolo K, Offner PJ, Orlando A, Slone DS, Mains CW, Carrick M, et al. The epidemiology of do-not-resuscitate orders in patients with trauma: a community level one trauma center observational experience. Scand J Trauma Resusc Emerg Med. 2015;23(1):1. [Link]
17. Mayr VD, Dünser MW, Greil V, Jochberger S, Luckner $\mathrm{G}$, Ulmer $\mathrm{H}$, et al.Causes of death and determinants of outcome in critically ill patients. Crit Care. 2006;10:R154. [PubMed]

18. Lakhey S, Karki B, Shrestha B, Shakya S, Pandey SB. Sepsis: a private hospital experience in Nepal. Journal of Institute of Medicine.2007;28(1).[Link] 